\title{
O IMPACTO ECONÔMICO PROPORCIONADO PELOS INVESTIMENTOS DE PESSOAS FÍSICAS E INFLUÊNCIA NA VIDA E NA FORMAÇÃO DE PATRIMÔNIO E DE RENDA
}

\begin{abstract}
Israel Ribeiro Alves ${ }^{1}$
RESUMO: O presente artigo possui como objetivo refletir e compreender sobre o impacto econômico proporcionado pelos investimentos de pessoas físicas, e verificar através de pesquisa bibliográfica além de artigos internet, e dissertações sobre o tema, o impacto econômico proporcionado pelos investimentos de pessoas físicas e influência na vida e na formação de patrimônio e de renda, sendo que as pessoas que buscam pela estabilidade econômica, possui cultura que influência sobre a maneira de como organizar suas finanças pessoais ou familiar $e$ tem influente papel na preparação da vida econômica, com relação aos objetivos de vida e definição do que querem ser ao passar dos anos e no resto da vida, sendo que os aspectos importantes para o seu bem estar, está na busca incessante pela comodidade, e a qualidade de vida, porém o descontrole nas finanças faz com que isso se torne um pouco mais difícil por diversas vezes. O bom gerenciamento do dinheiro, não é tarefa fácil, mas torna-se necessário para atender as necessidades que surgem na vida. E organizar as finanças pessoais é algo relevante na vida de todos, dificuldades na gerência dos recursos são mais frequentes, o que pode ser ocasionado pela falta de conhecimento perante a educação financeira, porem quando bem estruturadas tona-se a porta de entrada para um futuro de forma tranquila e sustentável para pessoas ou famílias que buscam estabilidade econômica.
\end{abstract}

Palavras-Chave: Finanças. Investimentos. Educação Financeira.

ABSTRACT: This article aims to reflect and understand the economic impact provided by the investments of individuals, and verify through bibliographic research in addition to internet articles, and dissertations on the topic, the economic impact and people provided and in the formation of heritage and income, and people who seek economic stability, have a culture that influences the way they organize their personal or family finances and has an influential role in the preparation of economic life, eating into the object and defining what they want to be when they pass. of years and the rest of life, and the significant aspects for your well-being, is the incessant search for comfort, and quality of life, but the lack of control in finances makes this become a little, but difficult several times. Good money management is not an easy task, but it becomes necessary to meet the needs that arise in life. And organizing personal finance is something relevant in everyone's life, difficulties in information about resources are more frequent, which can be caused by the lack of knowledge regarding education, financial, but when well-structured it becomes the gateway to a future in a peaceful and sustainable way for people or families looking for economic stability.

Keywords: Competitive advantage. Innovation.

\footnotetext{
${ }^{1}$ Mestrando em administração, pela Must University (Florida- USA). Administrador e consultor com registro no CRA-SC 28764. Graduado no curso de administração de empresas pela Faculdade de Ciências Administrativas e Contábeis- Centro Universitário da Grande Dourados- UNIGRAN. Pós- graduação em MBA executivo em administração com ênfase em recursos humanos. Centro Universitário da Grande Dourados, UNIGRAN. E-mail: israelribeiroalves@gmail.com
} 


\section{INTRODUÇÃO}

Este paper apresenta pesquisa investigativa através de websites, e bibliografia, por meio de artigos com o tema sobre o impacto econômico proporcionado pelos investimentos de pessoas físicas e influência na vida e na formação de patrimônio e de renda, que buscam novas alternativas na formação de patrimônio aumentar sua renda, que diante de tantas possibilidades para cumprir esse objetivo optam na busca do mercado de financeiro.

Investimento é o ato de aplicar o dinheiro esperando obter algum benefício ou lucro, o que se diferencia de economizar ou gastar, e como o mercado atual está cada vez mais acessível, e com informações detalhadas para que as pessoas tenham melhor entendimento e usufruindo das melhores escolhas para o seu perfil sem a necessidade de uma assessoria financeira especializada.

Investir não consiste apenas em aplicar seu capital em determinada empresa, pois o mercado de ações é volátil e complexo, é necessária uma investigação minuciosa sobre o investimento, com analise de todos os dados disponíveis, e escolha deve ser feita com muita cautela, considerando alguns fatores, como o perfil do investidor, nível de risco que está disposto a correr, o montante de capital disponibilizado, o tempo como curto ou longo prazo, dando assim uma maior sustentação e chance de se obter sucesso e o desejado retorno, evitando prejuízos futuros, e compondo uma carteira de ativos com investimentos rentáveis e de baixos riscos.

\section{DESENVOLVIMENTO - REVISÃO DE LITERATURA}

\section{MERCADO FINANCEIRO DE INVESTIMENTOS}

O mercado financeiro é o local onde o dinheiro é gerido, intermediado, oferecido e procurado, por meio de canais de comunicação que se entrelaçam na formação de sistemas.

É denominado mercado financeiro para títulos de dívida de curto prazo, e caracteriza-se pelo prazo de vencimento das reivindicações que estão sendo transacionadas, nada mais é do que um grande fundo, do qual se pode sacar, ou no qual se pode depositar recursos. 
Segundo Massaro (2015), investir significa empregar o dinheiro de forma a obter lucro, ou ainda, realizar um sacrifício de consumo no momento presente, na expectativa deque se tenha ainda mais dinheiro no futuro. As pessoas físicas lidarem com o dinheiro diariamente, o que falta é conhecimento de como fazer uma aplicação financeira que lhe traga maior rentabilidade. Para que se faça uma aplicação financeira bem-sucedida, a tomada de decisão do investimento pode levar em conta dados concretos que reflitam a situação atual da pessoa física bem como a que busca para o futuro.

$\mathrm{O}$ mercado financeiro existe porque em um dado momento, alguns agentes econômicos poupam mais do que investem enquanto outros investem mais do que poupam, sendo necessário transferir recursos das unidades que apresentam níveis de poupança para as unidades que necessitam de recursos para investir, de modo a obter a maior otimização da aplicação dos recursos disponíveis na economia e o mais alto nível de satisfação possível.

\section{INVESTIMENTOS TEMPORÁRIOS}

Os investimentos temporários são as aplicações de recursos financeiros, em valores mobiliários, em títulos e outros direitos disponíveis para o mercado, que são resgatáveis em determinados períodos de tempo, com a intenção e objetivo de obter lucros com a negociação desses ativos.

De acordo com (RIBEIRO, 2014, p. 44, 45). Os excessos de dinheiro que integram o saldo das contas caixa e ou conta bancária de movimentação, enquanto não utilizados para atender compromissos já adquiridos ou para contrair novos ativos, estes podem ser investidos, tendo em vista um retorno financeiro futuro, sendo que os prazos poderão variar entre Temporários a Longo Prozo e Permanentes.

De acordo com. (IUCÍCIBUS et. al. 2000 p. 83). "A classificação desses investimentos temporários deverá ser feita em função do tipo de investimento, do prazo de resgate e considerando, ainda, a própria intenção da empresa quanto à época em que pretende resgatar os títulos”.

Para (PARREIRA, 2008). Os investimentos temporários se caracterizam como “as aplicações de recursos financeiros em títulos e valores mobiliários resgatáveis em 
determinados períodos de tempo, com o objetivo de compensar perdas inflacionárias com as disponibilidades”.

A característica dos investimentos temporários, tem esse tratamento por adquiridos pelas empresas que possuem a intenção de obter rendimentos especulativos, e sem interesse em mantê-los, e por esse motivo são contabilizados no grupo Ativo Circulante.

\section{I.I Finanças \\ 1.2 Pessoais}

Segundo Pires (PIRES, 2006). Tratar as finanças pessoais como uma área de conhecimento sistemático e transmissível, no âmbito da ciência econômica, é uma necessidade contemporânea. Essa necessidade e aumenta a medida que cada indivíduo vai se tornando uma unidade produtiva autônoma na sociedade do conhecimento, um detentor de capital humano habilidades, conhecimentos e capacidades adquiridos, geralmente por meio de estudos, aplicáveis à geração de bens e serviços que se associa aos detentores de outros tipos de capital físico, financeiro etc.

As finanças pessoais possibilitam estudos para estabelecer análises sobre as condições de financiamento das aquisições de bens e serviços necessários à satisfação das necessidades e desejos individuais. A educação financeira, matéria restrita ao campo das finanças, ganha espaço institucional, com isso integrando definitivamente como área da Educação. O artigo 205 da Constituição Federal derg88 qualifica a educação financeira como direito de todos, dever do Estado e da família e deve ser promovida com a colaboração da sociedade.

A Constituição Federal de 1988 em seu artigo 2II exige que a União os estados, o Distrito Federal e os municípios organizem os diferentes sistemas de ensino em regime de colaboração um dos aspectos fundamentais das finanças pessoais é a elaboração do planejamento financeiro a ser destacado na próxima subseção, em que será abordada a importância que os indivíduos consigam garantir estabilidade financeira no futuro, controlando e planejando no presente. 


\section{PLANEJAMENTO FINANCEIRO}

Ao longo do tempo, as dificuldades financeiras são detectadas em vários fatores, basicamente em relação aos baixos salários, acesso ao crédito devido as facilidades apresentadas, a falta de capacidade de pagamento, além dos juros abusivos, práticas consumistas e principalmente ausência de educação financeira.

Pelas próprias características de boa parte das famílias, a falta de planejamento financeiro dificilmente é apontada como um fator relevante e, ao mesmo tempo, é aquela que está diretamente sob o controle dos indivíduos, por isso, "o planejamento financeiro pessoal significa estabelecer e seguir uma estratégia precisa, deliberada e dirigida para a acumulação de bens e valores que irão formar o patrimônio de uma pessoa e de sua família.

No entendimento de Leal e Nascimento (2009) o planejamento financeiro se pauta em três grandes pontos.

I) Como aproveitar as oportunidades de investimento que o mercado propõe.

II) Identificar o grau de endividamento aceitável.

III) Determinar a parcela dos lucros aferidos.

Conforme (MACEDO, 2007, p. 26), defende que o "planejamento financeiro é o processo de gerenciar seu dinheiro com o objetivo de atingir a satisfação pessoal.”

Numa família em que as metas de gerenciamento financeiro forem diferentes, dificilmente o plano financeiro terá poucas possibilidades de sucesso, estabelecendo administração por forças diferentes criando problema por não existir consenso de objetivos, pois pode ser conflitante o comportamento, enquanto um se empenha na redução de gastos, outro extrapolam com isso elimina-se os efeitos esperados que a teoria do planejamento se propõe.

Para execução do planejamento financeiro se faz necessário a utilização de planilhas financeiras, fluxos de caixa para que se torne possível identificar os gastos necessários e eliminar os excessivos de acordo com a renda obtida, é necessário o entendimento sobre a relação entre o dinheiro e as variáveis que influenciam o comportamento das pessoas, como status, poder e luxo. 


\section{CONCLUSÃO}

O objetivo deste trabalho é contribuir para o esforço contínuo para compreender o impacto econômico proporcionado pelos investimentos de pessoas físicas e influência na vida e na formação de patrimônio e de renda.

O mercado de capitais é o segmento do mercado financeiro que conecta companhias e investidores de forma direta, e são dois os parâmetros, para um crescimento saudável com empresas dispostas a abrir seu capital, e investidores dispostos a investir.

As vantagens do mercado de capitais vão de alternativa para aquisição de novos sócios para as companhias até diversificações e distribuição de risco, bem como democratização do acesso ao capital e maior liquidez e eficiência.

Constatou-se que os motivos que impedem o crescimento econômico pleno existem e encontram-se no ainda baixo nível de educação financeira, má conjuntura econômica e imaturidade das empresas brasileiras. Entretanto, é possível analisar um avanço no que se refere à modernização do mercado de capitais atrelado ao desenvolvimento econômico, dos quais resultam em um aperfeiçoamento constante no mercado de capitais e, consequentemente, um bom número de inscritos na Bolsa de valores.

É notável que este tema é ainda pouco explorado propõe pesquisas futuras no acerca do tema relatados neste artigo, e pode ser desenvolvido de modo significativo para agregar maior conhecimento, sem dúvidas esse tema é muito importante para que e apensar de todos os efeitos negativos, não só econômicos, causados pela pandemia, o brasileiro mostrou-se resiliente devido ao aumento significativo do número de investidores pessoas físicas na Bolsa de Valores, e em relação ao grande interesse no mercado de ações é recomendado um conhecimento mais aprofundado no mercado financeiro, para acompanhar as oscilações da bolsa e tomar as melhores decisões de compra e venda de ações , e é de grande necessidade que os estudos sobre o tema continuem, e que possa ser apresentado cada vez mais o problema de forma clara e objetiva. 


\section{REFERÊNCIAS BIBLIOGRÁFICAS}

IUCÍCIBUS, S. d., MARTINS, E., \& GELBCKE, E. R. (2000). Manual decontabilidade das sociedades por ações. (5). (Atlas, Ed.) São Paulo, São Paulo, Brasil: Atlas. Acesso em 23 de II de 202I, disponível em https://repositorio.ucs.br/xmlui/bitstream/handle/rr338/r675/TCC\%20Janete\%20Dal $\% 20$ Lago.pdf?sequence $=\mathrm{I} \&$ is Allowed $=\mathrm{y}$

MACEDO, J. J. (2007). A árvore do dinheiro. guia para cultivar sua independência financeira. (Elsevier, Ed.) Rio de Janeiro, Rio de Janeiro, Brasil: Elsevier. Acesso em 24 de II de 202I, disponível em https://docplayer.com.br/23580768-O-impacto-do-statusno-planejamento-financeiro-pessoal-estudo-de-caso-com-os-advogados-deflorianopolis-santa-catarina.html\#show_full_text

PARREIRA, P. H. (o2 de 2008). Material didático contabilidade avançada -encarte I. (U. C. Goiás, Ed.) Goiânia, Goias., Brasil: Universidade Católica do Goiás. Acesso em 23 de II de 2021, disponível em https://repositorio.ucs.br/xmlui/bitstream/handle/rr338/r675/TCC\%20Janete\%20Dal $\% 20$ Lago.pdf? sequence $=\mathrm{I} \&$ is Allowed $=\mathrm{y}$

PIRES, V. (2006). Finanças Pessoais Fundamentos e Dicas. (Atlas). (Atlas, Ed.) Piracicaba, São Paulo, Brasil. Acesso em 23 de il de 2021, disponível em https://admpg.com.br/2020/anais/arquivos/08092020_090802_5f_feazeae64d.pdf RIBEIRO, O. M. (2014). Contabilidade Avançada. (4). (Saraiva, Ed.) São Paulo, São Paulo, Brasil: Saraiva. Fonte: http://conic-semesp.org.br/anais/files/2015/trabalhoIoooorg566.pdf 